Erratum

\title{
Erratum to: Experimental Study and Numerical Analysis on Mechanical Behavior of T-shape Stiffened Orthotropic Steel- concrete Composite Bridge Decks
}

\author{
Xu Jiang ${ }^{1}$, Qingtian Su ${ }^{1, *}$, Xu Han ${ }^{1}$, Changyu Shao ${ }^{2}$, and Liang Chen ${ }^{2}$ \\ ${ }^{1}$ Department of Bridge Engineering, College of Civil Engineering, Tongji University, 1239 Siping Road, Shanghai, 200092, China \\ ${ }^{2}$ Shanghai Municipal Engineering Design Institute (Group) Co., Ltd., 901 Zhongshanbeier Road, Shanghai, 200092, China
}

() KSSC and Springer 2017

Erratum to: International Journal of Steel Structures 17(3): 893-907 (2017) DOI 10.1007/s13296-017-9004-y

Keywords:

Keywords are missing in the original version of the article. The Keywords should be as following:

Keywords: Composite bridge deck, Experiment, Numerial modelling, Mechanical behavior

published online December 31, 2017

C KSSC and Springer 2017

*Corresponding author

Tel: +8621 65986616, Fax: +862165981030

E-mail: sqt@tongji.edu.cn 